\title{
Studi Komunikasi Budaya di Kota Padang (Akulturasi Budaya Minangkabau Pada Etnis Tionghoa di Kota Padang)
}

\author{
Kezia Natalia Sjofjan, Suzy S. Azeharie \\ kezianatalia018@gmail.com,suzya@fikom.untar.ac.id \\ Fakultas Ilmu Komunikasi Universitas Tarumanagara
}

\begin{abstract}
The title of this research is the acculturation of Minangkabau culture against chinese society in Padang city. The purpose is to understand the acculturation culture of Minangkabau against chinese society in Padang. This research carried out using qualitative approach with phenomenal methodology. The research conducted using semi structured interview toward five chinese individuals. The data for this research is obtained from interviews, direct observations and other former researches. The main theory that is used in the research is cultural element from Larry A. Samovar, Richard E. Porter and Edwin R. McDaniel which consist of historical, religion, value, social organization and language. The research concluded that there is an acculturation of Minangkabau culture towards Chinese in Padang, such as language, social organization, value and history. Reason being is because there is a social interaction and openness between the two ethnicity.
\end{abstract}

Keywords: Cultural communication, cultural acculturation, Chinese Society

\begin{abstract}
Abstrak
Penelitian berjudul Studi Komunikasi Budaya Di Kota Padang (Akulturasi Budaya Minangkabau Pada Etnis Tionghoa di Kota Padang) ini dilakukan untuk mengetahui akulturasi budaya Minangkabau pada etnis Tionghoa di kota Padang. Penelitian ini menggunakan pendekatan kualitatif melalui metode fenomenologi. Penelitian akan menggunakan wawancara semi terstruktur terhadap lima informan etnis Tionghoa. Data penelitian yang diperoleh bersumber dari wawancara, observasi dan studi pustaka. Teori yang digunakan dalam penelitian adalah elemen budaya dari Larry A. Samovar, Richard E. Porter dan Edwin R. McDaniel yakni sejarah, agama, nilai, organisasi sosial dan bahasa. Penelitian ini menemukan adanya akulturasi budaya Minangkabau pada etnis Tionghoa di kota Padang yakni bahasa, organisasi sosial, nilai dan sejarah yang terjadi karena adanya interaksi sosial dan saling keterbukaan antara etnis Minangkabau dan etnis Tionghoa.
\end{abstract}

Kata Kunci: Komunikasi Budaya, Akulturasi Budaya, Etnis Tionghoa

\section{Pendahuluan}

Kota Padang merupakan ibu kota Provinsi Sumatera Barat yang penduduknya identik dengan etnis Minangkabau atau Minang. Menurut Erniwati dalam bukunya yang berjudul 140 Tahun Heng Beng Tong Sejarah Perkumpulan Tionghoa, perantau pertama yang datang ke wilayah Padang adalah etnis Minangkabau yang kemudian menjadikan Padang sebagai wilayah rantau mereka. Arus migrasi yang terus berdatangan dari daerah pedalaman menjadikan Padang semakin ramai oleh etnis Minangkabau sehingga etnis mereka menjadi sangat dominan dalam struktur masyarakat Padang atau dikenal sebagai urang awak (Erniwati, 2016). 
Derasnya arus migrasi akhirnya melahirkan budaya Minang di kota Padang. Budaya adalah tatanan pengetahuan, pengalaman, kepercayaan, nilai, sikap, makna, hirarki, agama, waktu, peranan, hubungan ruang, konsep alam semesta, objek-objek materi dan milik yang diperoleh sekelompok besar orang dari generasi ke generasi melalui usaha individu dan kelompok (Mulyana dan Rakhmat, 2005).

Sementara Musyair Zainuddin dalam bukunya Ranah Minang dan Lingkungan Hidup mengungkapkan budaya Minangkabau banyak disamakan dengan adat Minangkabau atau budaya alam Minangkabau. Penyampaian adat Minangkabau dilakukan dari mulut ke mulut atau dengan pembicaraan sehingga adat itu berada dalam pikiran setelah dilaksanakan tampilannya menjadi budaya (Zainuddin, 2014).

Seiring berjalannya waktu etnis Tionghoa mulai berdatangan di kota Padang. Kedatangan kelompok ini ke Padang menurut Muchlis Awwali dalam buku Pelangi Di Minangkabau mengatakan kedatangan etnis Tionghoa disebabkan dua faktor yakni berdagang dan mencari kehidupan yang layak (Awwali, 2015). Pada abad 19 kota Padang menurut Gan Hok Liong dalam buku Sejarah Panjang 150 Tahun Himpunan Tjinta Teman menjadi pusat pemerintahan Hindia Belanda untuk wilayah Sumatera. Sejak pemerintah Hindia Belanda mendirikan kantor-kantor dagang di Padang banyak pedagang-pedagang dari Eropa atau pedagang Tionghoa dari Malaka, Singapura dan Tiongkok melakukan kerjasama dengan pedagang Minangkabau (Liong, 2013).

Setiap pendatang menurut Naim dalam buku Muchlis Awwali yang berjudul Pelangi Di Minangkabau bertindak sebagai penyalur dari budaya asal dengan menyesuaikan diri dan berorientasi pada budaya yang ada di tempat tujuan. Dalam hal ini pendatang akan membawa budaya asal ke tempat tujuannya dan berhadapan dengan budaya yang saling berbeda (Awwali, 2015).

Hal yang sama terjadi pada kelompok Tionghoa di Padang. Sejalan dengan waktu terjadilah komunikasi antarbudaya antara etnis Tionghoa dan Minangkabau di kota Padang. Komunikasi antarbudaya menurut Andrea L. Rich dan Dennis M. Ogawa dalam buku Alo Liliweri adalah komunikasi antara orang-orang yang berbeda kebudayaannya seperti beda suku bangsa, etnik, ras dan kelas sosial (Liliweri, 2002). Melalui komunikasi antarbudaya terjadi pencampuran budaya atau yang kerap disebut dengan akulturasi budaya.

Akulturasi budaya menurut Koentjaraningrat dalam bukunya yang berjudul Pengantar Ilmu Antropologi adalah sebuah proses sosial yang timbul bila suatu kelompok manusia dengan suatu kebudayaan tertentu dihadapkan dengan unsurunsur dari suatu kebudayaan asing sehingga unsur-unsur kebudayaan asing tersebut lambat laun diterima dan diolah ke dalam kebudayaan sendiri tanpa menyebabkan hilangnya kepribadian kebudayaan itu sendiri (Koentjaraningrat, 2015).

Akulturasi budaya Minang pada etnis Tionghoa di kota Padang dapat dilihat melalui kajian elemen budaya menurut Larry A. Samovar, Richard E. Porter dan Edwin R. McDaniel. Lima elemen budaya tersebut adalah sejarah, agama, nilai, organisasi sosial dan bahasa (Samovar, Porter dan McDaniel, 2010). Akulturasi terjadi karena adanya pertemuan dua latar belakang budaya yang berbeda. Pertemuan dua latar belakang budaya yang berbeda tersebut mencakup sejarah, agama, nilai, organisasi sosial dan bahasa sehingga akulturasi dapat dilihat melalui lima elemen budaya tersebut.

Masih dalam buku yang sama dikatakan sejarah berhubungan dengan asal suatu budaya. Sejarah memberitahukan anggotanya segala sesuatu yang dianggap penting dan mengidentifikasi prestasi budaya yang pantas dibanggakan. Melalui 
sejarah seseorang mengenal dan memahami agama. Agama adalah aktivitas yang dominan dan terorganisasi serta meliputi kepercayaan, upacara, ritual, tabu dan perayaan. Agama memiliki nilai-nilai yang menjadi pedoman dalam kehidupan seseorang sedangkan nilai merupakan pedoman tingkah laku yang dianut oleh seseorang. Nilai-nilai tersebut kemudian diterapkan dalam lingkungan organisasi sosial tempat orang tersebut berada. Dalam organisasi sosial biasanya merujuk pada sistem sosial yang menetapkan jaringan komunikasi dan mengatur norma pribadi, keluarga dan tingkah laku sosial sedangkan bahasa adalah alat berkomunikasi (Samovar, Porter dan McDaniel, 2010).

Berdasarkan latar belakang tersebut rumusan masalah utama dalam penelitian ini adalah bagaimana akulturasi budaya Minangkabau pada etnis Tionghoa di kota Padang? Tujuan penulis melakukan penelitian mengenai akulturasi budaya Minangkabau pada etnis Tionghoa di kota Padang karena ingin mengetahui akulturasi budaya Minangkabau yang terjadi pada etnis Tionghoa di kota Padang. Penulis memilih menggunakan teori elemen budaya menurut Larry A. Samovar, Richard E. Porter dan Edwin R. McDaniel karena penelitian mengenai akulturasi yang dilihat dari lima elemen budaya ini belum pernah ada yang meneliti. Melalui teori elemen budaya, penulis hendak mengupas akulturasi budaya Minagkabau pada etnis Tionghoa melalui komponen sejarah, agama, nilai, organisasi sosial dan bahasa yang tidak dilakukan oleh penelitian lainnya.

\section{Metode Penelitian}

Dalam penelitian ini penulis menggunakan metode penelitian kualitatif dengan pendekatan fenomenologi. Menurut Ariesto Hadi Sutopo dan Adrianus Arief dalam bukunya yang berjudul Terampil Mengolah Data Kualitatif Dengan NVIVO penelitian kualitatif adalah penelitian yang ditunjukkan untuk mendeskripsikan dan menganalisis fenomena, peristiwa, aktivitas sosial, sikap, kepercayaan, persepsi dan pemikiran seseorang secara individual maupun kelompok (Sutopo dan Arief, 2010). Sementara menurut Bogdan dan Biklen dalam buku Muri Yusuf yang berjudul Metode Penelitian Kuantitatif, Kualitatif dan Penelitian, fenomenologi merupakan suatu tipe atau jenis penelitian kualitatif yang berusaha memahami makna dari suatu peristiwa dan interaksi dalam situasi tertentu. Penelitian fenomenologi selalu difokuskan pada menggali, memahami dan menafsirkan arti fenomena, peristiwa dan hubungannya dengan orang-orang biasa dengan situasi tertentu (Yusuf, 2015). Penulis menggunakan metode tersebut karena sejalan dengan perumusan masalah penulis yaitu untuk mengetahui akulturasi budaya Minangkabau pada etnis Tionghoa di kota Padang.

Subjek penelitian penulis adalah etnis Tionghoa di kota Padang sedangkan objek penelitian adalah akulturasi budaya Minangkabau. Data yang diperlukan penulis diperoleh berdasarkan metode pengumpulan data melalui observasi, wawancara dan studi pustaka. Lima narasumber yang diwawancarai oleh penulis yakni Edy Utama selaku pengamat budaya Minangkabau, Charlie Gunawan atau yang dikenal dengan Gho Tjeng Lie selaku Humas di Heng Beng Tong yaitu perkumpulan etnis Tionghoa di kota Padang sejak tahun 2005 sampai sekarang, Muhammad Damhuri selaku sastrawan Indonesia asal Minangkabau dan filsafat. Selanjutnya Felix dan Tamami selaku pasangan pengantin yang menggunakan unsur adat Minangkabau yaitu melempar beras kunyit saat prosesi penjemputan pengantin perempuan meskipun tidak menghilangkan adat Cina pada prosesi tersebut. 
Sementara Stacey Jessica dan Indra Aprianto selaku pasangan pengantin yang menggunakan unsur adat Minangkabau yaitu baju adat Minangkabau pada foto prewedding, tari piring pada pesta pernikahan dan pelemparan beras kunyit yang dilakukan pada waktu yang bersamaan dengan proses lamaran dan peresmian rumah baru.

Untuk membuktikan keabsahan data dari penelitian ini, penulis menggunakan teknik pemeriksaan keabsahan data dengan teknik triangulasi. Menurut Lexy J. Moleong dalam bukunya yang berjudul Memahami Penelitian Kualitatif, teknik triangulasi adalah teknik pemeriksaan keabsahan data yang memanfaatkan sesuatu yang lain. Dengan triangulasi peneliti dapat melakukan pengecekan temuannya atau sebagai pembanding terhadap berbagai sumber, metode atau teori (Moleong, 2012).

\section{Hasil Temuan dan Diskusi}

Berdasarkan hasil wawancara dan pengamatan yang dilakukan oleh penulis terdapat akulturasi pada pernikahan etnis Tionghoa di kota Padang yakni etnis Tionghoa Padang menggunakan adat pelemparan beras kunyit pada acara pernikahan. Charlie Gunawan mengatakan bahwa adat pelemparan beras kunyit merupakan adat pernikahan yang berasal dari Minangkabau yang bertujuan untuk mengusir roh-roh jahat atau bala agar tidak menganggu kelancaran acara pernikahan. Dalam pernikahan di Cina yang dilempar adalah manisan saat pengantin laki-laki akan masuk kerumah pengantin perempuan. Melemparkan manisan bertujuan untuk menyogok para Dewa agar tidak mengganggu pengantin laki-laki dan perempuan yang akan bertemu. Namun etnis Tionghoa Padang menggunakan beras kunyit kemudian dicampurkan dengan bitai. Bitai merupakan nyiru bundar milik Tionghoa yang diberikan huruf Suangsi (wawancara dengan Charlie Gunawan pada tanggal 14 September 2018 Pukul 10.07 WIB).

Stacey Jessica dan Indra Aprianto merupakan pasangan pengantin etnis Tionghoa Padang yang memilih tema untuk resepsi pernikahan dengan mencampurkan unsur adat Cina dan Minangkabau mulai dari dekorasi ruangan yang menggunakan warna emas dan merah sebagai warna asli Minangkabau, tema foto prewedding menggunakan pakaian adat Minang, acara pernikahan menghadirkan tari piring dan barongsai dan adat pelemparan beras kunyit yang merupakan adat pernikahan Minangkabau. 
Gambar 1. Foto Prewedding Stacey Jessica dan Indra Aprianto

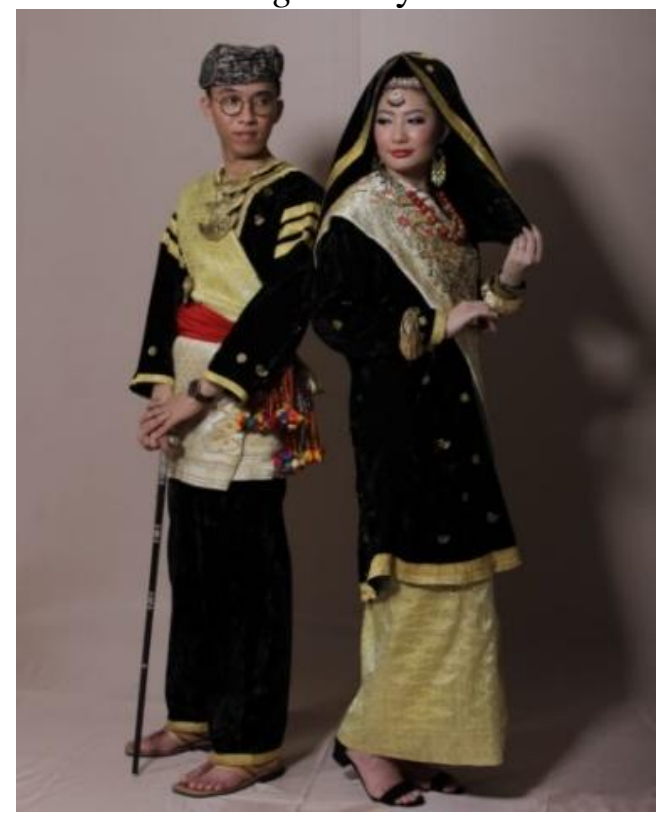

Sumber: Dokumentasi Penulis (2018)

Selain itu pasangan pengantin Felix dan Tamami yang merupakan etnis Tionghoa dan Jepang juga menikah dengan menggunakan campuran unsur adat Cina dan Minangkabau pada prosesi penjemputan calon pengantin perempuan. Adat yang digunakan pada prosesi penjemputan calon pengantin perempuan adalah adat pelemparan beras kunyit.

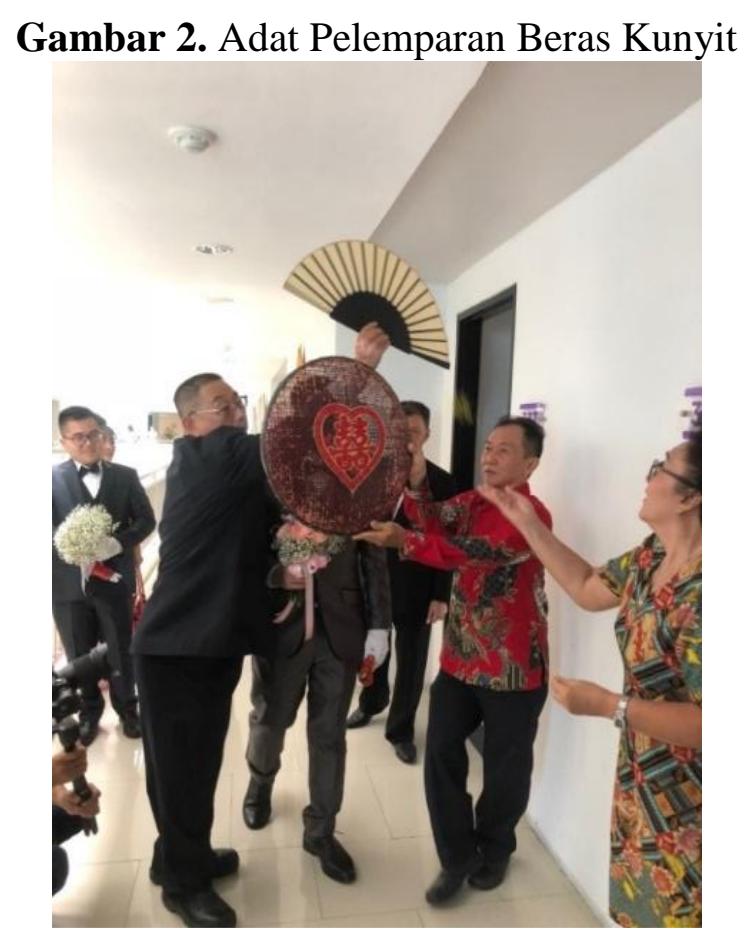

Sumber: Dokumentasi Penulis (2018)

Sementara berdasarkan hasil wawancara penulis dengan Edy Utama seorang budayawan Minangkabau terungkap bahwa secara konsepsional budaya 
Minangkabau terdiri dari empat tiang utama yakni adat nan sabana adat, adat nan diadatkan, adat nan teradat dan adat istiadat. Adat nan sabana adat merupakan hukum alam sesuatu yang abadi yang Tak Lapuk Dek Hujan, Tak Lakang Dek Paneh sepanjang keberadaan budaya Minangkabau. Artinya adat merupakan ajaran yang tidak bisa berubah yang sifatnya universal dan bersumber dari hukum alam. Dapat diibaratkan seperti Pancasila di Indonesia sesuatu yang menjadi sumber dari pada perilaku dan semua adat istiadat yang digunakan oleh adat nan diadatkan, adat nan teradat dan adat istiadat yakni Adat Basandi Syarak, Syarak Basandi Kitabullah. Sedangkan konsep adat nan diadatkan, adat nan teradat dan adat istiadat merupakan sebuah budaya yang usang-usang diperbaharui, lapuak-lapuak dikajangi artinya jika dianggap usang dan ketinggalan zaman maka akan diperbaharui sehingga sifatnya tidak abadi atau fleksibel mengikuti perkembangan zaman namun tetap berpegang pada prinsip adat nan sabana adat (wawancara dengan Edy Utama pada tanggal 25 November 2018 pada pukul 12.05 WIB).

Muhammad Damhuri seorang sastrawan asal Minangkabau mengatakan bahwa falsafah Dima Bumi Dipijak, Disinan Langik Dijunjuang menjadi pandangan hidup orang Minangkabau ketika merantau agar selalu menyesuaikan diri dengan kebudayaan orang lain. Misalnya seorang perantau tidak mungkin menganggap dirinya sebagai orang Minang yang kebudayaannya adiluhur dan hebat sedangkan ia tinggal di Jakarta. Maka perantau tersebut akan menyerap pelajaran mengenai orang Jakarta seperti dalam lingkungan dan pergaulan sehari-hari.

Etnis Tionghoa Padang yang sudah hidup lama di Minangkabau menyerap pelajaran falsafah tersebut. Salah satu contohnya adalah orang Minang senang duduk santai atau ngopi di warung, maka orang Tionghoa membuka warung sebagai tempat bersantai atau ngopi. Bahkan daerah Pondok di kota Padang terkenal dengan daerah kedai kopi yang pemiliknya semua etnis Tionghoa namun yang duduk kebanyakan adalah orang Minang. Jenis hidangan yang dijual juga sama dengan yang disediakan oleh orang Minang di warung-warung seperti teh talua, ketan duren dan bubur kacang padi bahkan cita rasanya konon lebih enak daripada warung-warung milik orang Minang. Ketika bulan puasa orang Minang memiliki tradisi pabukoan yaitu menyediakan menu makanan atau hidangan untuk berbuka puasa seperti es cendol, es campur, kolak dan berbagai macam makanan. Etnis Tionghoa juga mengikuti hal tersebut dengan menjual pabukoan bahkan lebih laris, lebih enak dan lebih terkenal termasuk oleh-oleh dari Sumatera Barat seperti keripik sanjai yang biasa dijadikan oleh-oleh yang membuatnya adalah orang Tionghoa Padang bukan orang Minang. Rendang yang dikemas dalam bungkusan juga merupakan hasil kreatifitas dari etnis Tionghoa Padang. Mulai dari rendang, keripik sanjai, gelamai sampai pada menumenu sederhana di warung-warung kopi cita rasanya jauh lebih enak dari pada buatan orang Minang (wawancara dengan Muhammad Damhuri pada tanggal 25 November 2018 pada pukul 10.17 WIB).

Edy Utama menambahkan bahwa jika dilihat di daerah pedalaman dahulu warung kopi buka sampai tengah malam dan orang Minang sangat menikmati hidup di warung hingga sekarang. Saat ini mulai dari kaum elit sampai kalangan bawah sejak pagi sudah berkumpul di warung untuk membicarakan berbagai hal seperti politik, ekonomi, filsafat dan sebagainya bahkan di daerah Pondok banyak terdapat warung kopi atau kedai kopi seperti Harum Manis dan Nanyo (wawancara dengan Edy Utama pada tanggal 4 November 2018 pada pukul 17.05 WIB).

Sementara Charlie Gunawan mengungkapkan bahwa agar dapat berbaur dengan orang Minang maka etnis Tionghoa Padang menyerap falsafah Minang Dima 
Bumi Dipijak, Disinan Langik Dijunjuang yang artinya harus bisa menyesuaikan diri dengan lingkungannya. Salah satu yang paling jelas terlihat dari etnis Tionghoa Padang adalah mereka fasih berbahasa Minang campur hingga saat ini. Selain itu falsafah Bulek Aia Dek Pambuluah, Bulek Kato Dek Mufakat yakni mengenai musyawarah dan mufakat. Musyawarah dan mufakat pada masyarakat Tionghoa biasanya dilakukan dalam acara rapat kongsi besar di Heng Beng Tong atau Hok Tek Tong dan jika dalam jumlah kecil diadakan di Jieshe Kongsi atau kongsi kecil seperti She Gho, Lie atau Kwee, Tjoa dan Kwa, Tan, Ong, Lim, Huang dan Kho. Namun bila lebih luas dan umum dilakukan dalam wadah See Hien Kiong yang mengurus semua masyarakat Tionghoa di kota Padang. Selain melalui rapat kongsi besar seperti Jieshe Kongsi dan See Hien Kiong jika masalah tidak terlalu besar maka musyawarah dan mufakat dapat dilakukan melalui rapat keluarga yang dipimpin oleh saudara laki-laki Ayah atau Ibu yang lebih tua.

Pada perhimpunan atau organisasi sosial seperti di kongsi-kongsi Heng Beng Tong dan Hok Tek Tong, bila diantara sesama anggota kongsi terdapat masalah perihal uang, hutang piutang dan sebagainya, misalnya A berhutang dengan B untuk keperluan dagang dan karena tidak mendapatkan pinjaman dari Bank maka A mencari alternatif lain dengan cara meminjam uang dengan B yang merupakan sesama anggota kongsi karena ketika dilantik menjadi anggota ada perjanjian antar sesama anggota namun ketika hutang tersebut ditagih A berkelit tidak mau membayar. Maka tidak boleh langsung melapor kepada polisi tapi harus melapor pada pengurus kongsi terlebih dahulu. Melapor kepada Twee Tauw yaitu ketua kelompok jika tidak bisa diselesaikan oleh Twee Tauw maka dilanjutkan kepada Conglie jika tidak bisa diselesaikan oleh Conglie maka akan dilanjutkan oleh Shako jika masalah tidak bisa diselesaikan juga maka akan diserahkan kepada polisi.

Selain musyawarah dan mufakat ada juga tenggang rasa. Tenggang rasa pada orang Minang dikenal dengan istilah urang awak yang artinya orang kita. Hal ini juga diterapkan oleh etnis Tionghoa Padang dalam arti teman seperti jika dalam berdagang dengan teman sendiri maka tenggang rasa diberikan dalam bentuk toleransi hutang satu bulan bisa diundur menjadi tiga bulan (wawancara dengan Charlie Gunawan di Villa Rangkai Permata pada tanggal 14 September 2018 Pukul 10.07 WIB).

\section{Simpulan}

Akulturasi budaya Minangkabau pada etnis Tionghoa di kota Padang dapat dilihat melalui adat pernikahan etnis Tionghoa yang menggunakan beras kunyit pada acara pernikahan yang bertujuan untuk mengusir roh jahat agar tidak mengganggu kelancaran acara pernikahan sebagai pengganti dari manisan yang kemudian berubah menjadi beras kunyit.

Selain itu etnis Tionghoa di kota Padang menyerap falsafah Minangkabau yaitu Dima Bumi Dipijak, Disinan Langik Dijunjuang yang artinya harus bisa menyesuaikan diri dengan lingkungannya dan falsafah Bulek Aia Dek Pambuluah, Bulek Kato Dek Mufakat yang artinya mengenai musyawarah dan mufakat.

Dalam kehidupan sehari-hari etnis Tionghoa Padang menggunakan bahasa percakapan harian yang menyerap gaya bahasa orang Minang yang disebut dengan dialek Tionghoa Pondok Padang dan masakan makan Minang yang dibuat oleh etnis Tionghoa Padang cita rasanya lebih enak dari pada masakan orang Minang.

Berdasarkan lima elemen budaya dari Larry A. Samovar, Richard E. Porter dan 
Edwin R. McDaniel yakni sejarah, nilai, organisasi sosial, agama dan bahasa hanya terdapat empat elemen budaya yang berpengaruh dalam akulturasi budaya Minangkabau pada etnis Tionghoa di kota Padang yakni bahasa, organisasi sosial, nilai dan sejarah.

\section{Ucapan Terima Kasih}

Penulis mengucapakn rasa terima kasih yang sebesar-besarnya kepada seluruh pihak yang telah membantu dan mendukung penulis selama proses penelitian ini berlangsung sampai dengan terbitnya publikasi atas hasil penelitian ini.

\section{Daftar Pustaka}

Awwali, Muchlis. (2015). Pelangi Di Minangkabau. Padang: SURI Surau Institute for Conservation

Erniwati. (2016). 140 Tahun Heng Beng Tong: Sejarah Perkumpulan Tionghoa 1876-2016. Depok: Komunitas Bambu.

Koentjaraningrat. (2015). Pengantar Ilmu Antropologi. Jakarta: Rineka Cipta

Liliweri, Alo. (2002). Makna Budaya Dalam Komunikasi Antarbudaya. Yogyakarta: LKiS Yogyakarta

Moleong, Lexy J. (2012). Metodologi Penelitian Kualitatif. Bandung: Remaja Rosdakarya.

Mulyana, D., \& Jalaluddin, R. (2005). Komunikasi Antarbudaya Panduan Berkomunikasi Dengan Orang-Orang Berbeda Budaya. Bandung: PT Remaja Rosdakarya

Samovar, Larry A, et al. (2010). Komunikasi Lintas Budaya. Jakarta: Salemba Humanika.

Sjarif, M., \& Azeharie, S. (2016). Studi Akulturasi Perayaan Kue Bulan Pada Etnis Tionghoa di Tangerang. Jurnal Komunikasi.

Sutopo, A. H., \& Adrianus Arif. (2010). Terampil Mengolah Data Kualitatif Dengan NVIVO. Jakarta: Prenada Media Group

Utami, Lusia Savitri Setyo. (2015). Teori-Teori Adaptasi Antar Budaya. Jurnal Komunikasi. 7(2). 180-197

Yusuf, Muri. 2015. Metode Penelitian: Kuantitatif, Kualitatif, dan Penelitian Gabungan. Jakarta: Kencana Prenada Media Group

Zainuddin, Musyair. (2014). Ranah Minang Dan Lingkungan Hidup. Yogyakarta: Penerbit Ombak 